Tropical Journal of Pharmaceutical Research February 2019; 18 (2): 357-364

ISSN: $1596-5996$ (print); 1596-9827 (electronic)

(c) Pharmacotherapy Group, Faculty of Pharmacy, University of Benin, Benin City, 300001 Nigeria.

\title{
A fast and validated chromatographic method for simultaneous determination of deferoxamine and D- penicillamine via chelate formation with metal ions in bulk and dosage forms
}

\author{
Hassan A Alhazmi ${ }^{1,2 \star}$, Zia ur Rehman ${ }^{1}$ \\ ${ }^{1}$ Department of Pharmaceutical Chemistry, College of Pharmacy, ${ }^{2}$ Substance Abuse Research Centre, Jazan University, Postal \\ Code 45142, Jazan, Saudi Arabia
}

*For correspondence: Email: haalhazmi@jazanu.edu.sa; Tel: +966 541433344

Sent for review: 2 November 2017

Revised accepted: 27 January 2019

\begin{abstract}
Purpose: To develop a chromatographic method for the determination of deferoxamine (DFX) and Dpenicillamine (D-PEN) by improving ultra violet (UV)-absorption via complex formation with $\mathrm{Fe}^{2+}$ and $\mathrm{Cu}^{2+}$ metal ions.

Methods: Chromatographic analysis was performed by Waters RP-HPLC system using a Symmetry® C (18) column with a mobile phase comprising $0.1 \%$ formic acid and methanol $(95: 5 \mathrm{v} / \mathrm{v})$. For complexation process, drug and metal ion solution were mixed in a ratio of 1:5 and the resulting complex directly analyzed. Validation and system suitability parameters (including chromatographic parameters) were determined.

Results: DFX-Fe $e^{2+}$ and D-PEN-Cu ${ }^{2+}$ complexes showed good UV absorption at $260 \mathrm{~nm}$ and were easily determined by the newly developed HPLC method. The developed method showed linearity over the concentration range of $8-96 \mu \mathrm{mL}^{-1}\left(R^{2}>0.999\right.$ for DFX and $>0.99$ for D-PEN). Precision and accuracy were also within acceptable limits (100.0 $\pm 2.0 \%)$.

Conclusion: The developed method is robust and validated, and satisfies all the system suitability requirements as per ICH guidelines. DFX injection and D-PEN capsule dosage forms can be successfully analysed with the proposed method. The method is simple, fast and cost-effective for the analysis of D-PEN and DFX individually, or simultaneously in bulk drugs as well as in capsule and parenteral formulations, using UV-detector.
\end{abstract}

Keywords: Deferoxamine, D-penicillamine, Chelate formation, Metal ions, HPLC, Dosage forms

\begin{abstract}
This is an Open Access article that uses a funding model which does not charge readers or their institutions for access and distributed under the terms of the Creative Commons Attribution License (http://creativecommons.org/licenses/by/4.0) and the Budapest Open Access Initiative (http://www.budapestopenaccessinitiative.org/read), which permit unrestricted use, distribution, and reproduction in any medium, provided the original work is properly credited.
\end{abstract}

Tropical Journal of Pharmaceutical Research is indexed by Science Citation Index (SciSearch), Scopus, International Pharmaceutical Abstract, Chemical Abstracts, Embase, Index Copernicus, EBSCO, African Index Medicus, JournalSeek, Journal Citation Reports/Science Edition, Directory of Open Access Journals (DOAJ), African Journal Online, Bioline International, Open-J-Gate and Pharmacy Abstracts

\section{INTRODUCTION}

Studies on the development of chelating agents have been growing steadily due to their wide range of applications in the field of nutritional supplements and pharmaceuticals [1-3]. Chelation therapy has been introduced for removing toxic metal ions such as mercury, arsenic and lead, and also for correct the biological levels of the essential metals and 
minimize the harmful effects due to their elevated concentrations. Deferoxamine (DFX; desferrioxamine) and D-penicillamine (D-PEN) are well known chelating drugs, used to treat iron and copper excesses inside the body. They have a tendency to form chelates with various divalent and trivalent metal ions [3-9].

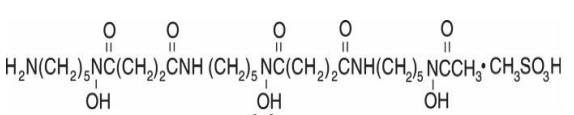

(a) (b)

Figure 1: Chemical structures of: a) deferoxamine mesylate, b) $D$-penicillamine

The chemical structures of DFX and D-PEN lack the presence of conjugation which is essential for UV light absorption above $200 \mathrm{~nm}$ region. Therefore, common detectors based on UV-Vis absorption cannot be used for detection of these drugs. On the other hand, fluorescence and mass detection are more specialized techniques, although they increase the cost of analysis. The UV absorption of chelating drugs lacking conjugation can be improved by means of charge transfer, when the analytes bind with metal ions such as $\mathrm{Fe}^{3+}, \mathrm{Fe}^{2+}$ and $\mathrm{Cu}^{2+}[10-12]$. Chelating drug-metal ion complex formation and their stability could be estimated based on hard and soft acid and base concept (HSAB). In general, hard metal ions prefer to bind with hard ligands while soft metal ions prefer to bind with soft ligands.

Previously, DFX was determined in bulk and dosage forms after complex formation with iron by chromatographic methods using fluorometric, electrochemical and mass detectors [13-15]. In addition, HPLC-based methods based on the application of post-column derivatization technique for the detection of DFX are available [16]. Similarly, various chromatographic methods for the detection of D-PEN in different traces have also been reported [17-24].

A survey of literature reveals that no HPLC-UV or UPLC-UV method has been reported for simultaneous determination of D-PEN and DFX after complexation with metal ions. However, information on the complexes of DFX and D-PEN with $\mathrm{Cu}^{+}, \mathrm{Cu}^{2+}, \mathrm{Fe}^{2+}$ and $\mathrm{Fe}^{3+}$ are well documented in the literature [25-28]. Therefore, the present study was undertaken to develop a rapid HPLC-UV method that can be applied for determination of mixtures of D-PEN and DFX using pre-injection complex formation with suitable metal ions such $\mathrm{Cu}^{2+}$ or $\mathrm{Fe}^{2+}$. The method development will rely on the stability and the reproducibility of a good chromatographic peak shapes of drug-metal ion complex as well as good separation between the drug-metal ion complexes.

\section{EXPERIMENTAL}

\section{Chemicals and reagents}

Reference standards of deferoxamine mesylate, $D$-penicillamine, copper sulphate pentahydrate and ferrous sulphate heptahydrate were procured from Sigma Aldrich. Formic acid and methanol were also procured from Sigma Aldrich. In-house Milli $Q$ water was used for preparation of solvent systems. Artamin capsules containing 150 mg D-Penicillamine (Sandoz, Austria) and Desferal ${ }^{\circledR}$ vial for injection, containing $500 \mathrm{mg}$ lyophilized deferoxamine mesylate powder (Novartis, Switzerland) were purchased from local hospital pharmacy store.

\section{Instrumentation and chromatographic conditions}

HPLC investigations were conducted on a Waters Breeze 1525 instrument using breeze LC2 software and separation was performed in Symmetry® $\mathrm{C}(18)$ column $(0.75 \mathrm{~cm} \times 4.6 \mathrm{~mm}$ i.d., particle size $3.5 \mu \mathrm{m})$ under benchtop conditions. The separation was achieved by using mobile phase at $1 \mathrm{~mL} / \mathrm{min}$ rate $(0.1 \%$ formic acid in water and methanol; 95:5 $\mathrm{v} / \mathrm{v}$ ), injection volume of $20 \mu \mathrm{L}$ and detector wavelength of 260 $\mathrm{nm}$ for a run time of $7 \mathrm{~min}$.

\section{Preparation of solutions}

\section{Mobile phase}

Formic acid solution (0.1\%) in water and methanol-HPLC grade were mixed to have ratio of 95:5 $\mathrm{v} / \mathrm{v}$, filtered through $0.45 \mu \mathrm{m}$ nylon filter and sonicated $30 \mathrm{~min}$.

\section{Standard drug stock solutions}

Standard stock solutions containing $0.005 \mathrm{M}$ of deferoxamine mesylate $(0.746 \mathrm{mg} / \mathrm{mL})$ and 0.005 $\mathrm{M}$ of $D$-penicillamine $(3.282 \mathrm{mg} / \mathrm{mL})$ were prepared by dissolving accurately weighed reference standards separately in Milli $Q$ water in a volumetric flask.

\section{Metal ion standard stock solutions}

Standard stock solutions containing $0.025 \mathrm{M}$ of iron (II) sulphate heptahydrate $(6.952 \mathrm{mg} / \mathrm{mL})$ and $0.025 \mathrm{M}$ copper (II) sulphate pentahydrate (6.244 $\mathrm{mg} / \mathrm{mL})$ were prepared by dissolving in water, and the solutions were filtered and sonicated for $10 \mathrm{~min}$. 


\section{Working standard solutions}

The working standard solutions for each drug were prepared separately by transferring $1 \mathrm{~mL}$ of the standard drug stock solution and $1 \mathrm{~mL}$ of the metal ion stock solution to $5 \mathrm{~mL}$. The volume was made up to $5 \mathrm{~mL}$ with $0.1 \%$ formic acid to obtain metal ion/drug molar concentration ratio of $5: 1$. This ratio showed stable and reproducible chromatographic peak shape and area (see Results and Discussion section). The mixture was sonicated for $5 \mathrm{~min}$ at $60^{\circ} \mathrm{C}$ to accelerate drug-metal ion complexation. The resulting solutions were further diluted with $0.1 \%$ formic acid to get the final drug concentrations of 20 $\mu \mathrm{g} / \mathrm{mL}$ before introducing them to the HPLC system for method development process. Similarly, for calibration curve, the final drug standard solutions of concentrations in range of 8 - $96 \mu \mathrm{g} / \mathrm{mL}$ containing both D-PEN-Cu${ }^{2+}$ and DFX-Fe ${ }^{2+}$ complexes were prepared using $0.1 \%$ formic acid as diluent.

\section{Sample stock solutions of formulations}

Deferoxamine mesylate: The contents of five injection vials were reconstituted with HPLC water and diluted with $0.1 \%$ formic acid to get the final concentration of $0.005 \mathrm{M}(0.746 \mathrm{mg} / \mathrm{mL})$.

D-penicillamine: The contents of ten capsules were taken out, and an amount corresponding to $16.41 \mathrm{mg}$ of $D$-penicillamine was diluted to $5 \mathrm{~mL}$ with water, filtered and sonicated for $30 \mathrm{~min}$.

Sample solution from dosage forms: The test solutions were prepared by adding $1 \mathrm{~mL}$ of each sample drug stock solution and $1 \mathrm{~mL}$ of each standard stock metal ion solution to $5 \mathrm{~mL}$ in a volumetric flask with $0.1 \%$ formic acid. The mixture was sonicated for $5 \mathrm{~min}$ at $60^{\circ} \mathrm{C}$. The resulting solution was diluted with $0.1 \%$ formic acid to get the final concentrations of 20,40 and $60 \mu \mathrm{g} / \mathrm{mL}$ for each drug.

Placebo stock and working solutions: The placebo solution for D-penicillamine capsule formulation was prepared by taking the equivalent amounts of excipients such as lactose and magnesium stearate into a $5 \mathrm{~mL}$ Eppendorf tube, and making up the volume with HPLC grade water, followed with mixing well. A placebo test solution was prepared same as sample test solution.

\section{Validation of method}

All validation and system suitability parameters including chromatographic parameters, linearity, LOD, LOQ, precision, accuracy, specificity, and solution stability were performed as per $\mathrm{ICH}$ guidelines. [31,32].

\section{Linearity}

Linearity was evaluated using regression analysis by plotting six concentrations $(8,16,32$, 64,80 and $96 \mu \mathrm{g} / \mathrm{mL}$ ) against their peak areas in six replicates.

\section{Accuracy and precision}

Three quality of control samples at low, medium and high (LQC, 16; MQC, 64 and HQC, 96 $\mu \mathrm{g} / \mathrm{mL})$, concentrations were selected for precision and accuracy determination. The samples were analyzed at different times on the same day, and the same analyses were performed over different days for determination of intra-day and interday precision.

The recoveries and their respective \% RSD were calculated. For dosage forms, test samples at 50, 100 and $150 \%$ of target concentration (40 $\mu \mathrm{g} / \mathrm{mL}$ ) were injected in six replicates, and the \% recoveries were determined.

\section{Quantification and limit of detection}

The LOD and LOQ were calculated as per the $\mathrm{ICH}$ and USP guidelines.

\section{Specificity}

The specificity of the proposed method was determined by examining the chromatograms for any interfering peaks from blank and placebo.

\section{Solution stability}

The test and standard solutions were evaluated for their stabilities at different storage conditions at MQC level $(64 \mu \mathrm{g} / \mathrm{mL})$. The solutions were kept at 20,4 and $-20( \pm 2){ }^{\circ} \mathrm{C}$ for 7,114 and 0 days respectively. They were analyzed at the end of each storage period and the results were compared with those of fresh solutions.

\section{Robustness}

To evaluate the robustness of the method, small deliberate changes were made in the ratio of mobile phase $( \pm 5 \%)$, detector wavelength $( \pm 5$ $\mathrm{nm})$ and flow rate $( \pm 0.1 \mathrm{~mL} / \mathrm{min})$ in the optimized chromatographic method. The effect of these small changes on the contents of D-PEN and DFX were evaluated in triplicate. 


\section{RESULTS}

\section{Validation data}

The research project was undertaken to develop a HPLC method for determination of DFX and DPEN via complex formation with polyvalent metal ions. After investigating different mobile phase compositions of aqueous and organic phases (methanol and acetonitrile), a mobile phase consisting of $0.1 \% \mathrm{HCOOH}$ and $\mathrm{CH}_{3} \mathrm{OH}$ (95:5 $\mathrm{v} / \mathrm{v}$ ) was found to be optimum at a flow rate of 1 $\mathrm{mL} / \mathrm{min}$. The data were obtained at a wavelength of $260 \mathrm{~nm}$, and the retention times of D-PEN$\mathrm{Cu}^{2+}$ and DFX-Fe ${ }^{2+}$ complexes were observed at 1.47 and $5.52 \mathrm{~min}$, respectively. The chromatograms obtained by using optimized chromatographic conditions are depicted in Figure 2. Furthermore, Figure 3 shows the chromatograms of selected metal ions using the developed HPLC conditions. Symmetrical peaks for both DFX-Fe ${ }^{2+}$ and D-PEN-Cu ${ }^{2+}$ complexes were obtained with excellent resolution and the tailing factors were less than 2. Overall, the system suitability parameters obtained by the finalized chromatographic condition were within acceptable limits, indicating the suitability of the system for conducting the experiment. The observed suitability parameters are summarized in Table 1.

The limit of detection and limit of quantification for D-PEN and DFX were found to be 1.180 and $3.085 \mu \mathrm{g} / \mathrm{mL}$, and 6.034 and $10.286 \mu \mathrm{g} / \mathrm{mL}$ respectively. No interfering peaks of matrix (blank and placebo) were observed at the retention times of the drug complexes, indicating the specificity of the developed HPLC method (Figure 3). The method was linear in the concentration range of $8-96 \mu \mathrm{g} / \mathrm{mL}$, with mean correlation coefficient $\left(R^{2}\right)$ values of 0.9906 and 0.9999 for D-PEN-Cu ${ }^{2+}$ and DFX-Fe ${ }^{2+}$, respectively, suggesting the linearity of the proposed method. The precision and accuracy results for D-PEN-Cu ${ }^{2+}$ and DFX-Fe ${ }^{2+}$ in the QC samples at LQC, MQC and HQC levels are shown in Table 2. The precision was expressed as \% RSD values of the peak areas, and was in the range of $0.2-1.3 \%$ for D-PEN-Cu ${ }^{2+}$, and 1.1 - $2.0 \%$ for DFX-Fe ${ }^{2+}$ in the intra-day analysis, whereas, for inter-day analysis, the precision was in the ranges of $0.2-0.7 \%$ and $0.6-1.5 \%$, respectively. To demonstrate the accuracy of the method, recovery was evaluated by standard addition method, and the results for both analytes were within 98.0 - $102.0 \%$ range. Representative chromatograms showing overlay of six replicate injections at LQC level $(16 \mu \mathrm{g} / \mathrm{mL})$ are depicted in Figure 4. All the solutions were found to be stable in the selected storage conditions. The solution stability was expressed as mean percent recovery calculated from the peak area under respective storage conditions. It was found to be in the range of $99.1-100.9 \%$ for D-PEN-Cu ${ }^{2+}$, and $99.2-100.3 \%$ for and $\mathrm{DFX}-\mathrm{Fe}^{2+}$. These results suggest that the proposed method can be operated in benchtop conditions (Table 3 ).

Robustness study was performed to investigate the effect of ratio of mobile phase $( \pm 5 \%)$, flow rates of 0.9 and $1.1 \mathrm{~mL} / \mathrm{min}$, and detector wavelengths of 255 and $265 \mathrm{~nm}$. No remarkable differences $(100 \pm 2 \%)$ were observed between the assay results obtained by employing the optimized analytical conditions and those obtained from the experiments in which small variations in chromatographic parameters were made. Thus, the method was robust for D-PEN and DFX assays for small variations in organic solvent ratio in the mobile phase, flow rate and detection wavelength. The robustness results are summarized in Table 4.

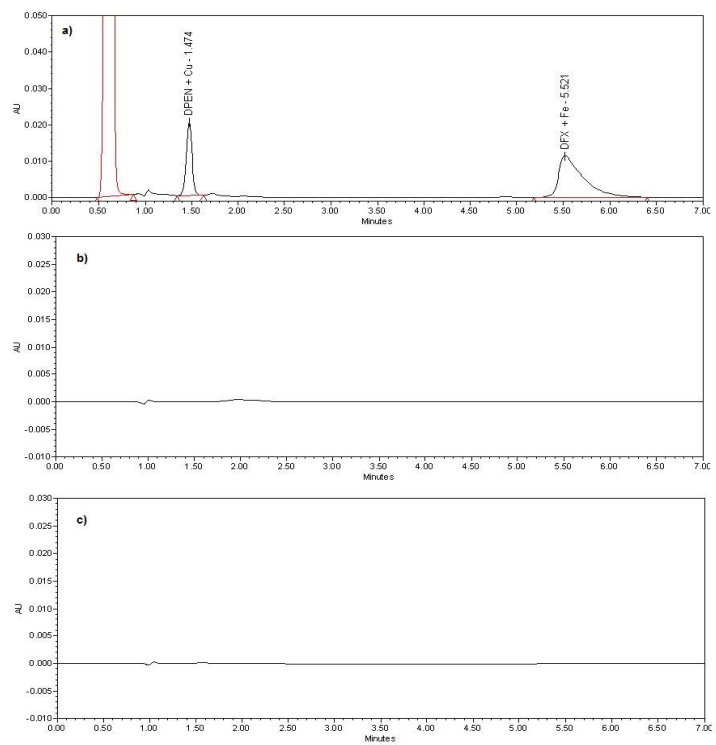

Figure 2: Representative chromatograms of a mixture of D-PEN-Cu ${ }^{2+}$ and DFX-Fe ${ }^{2+}$ complexes (a); mixture of D-PEN and DFX pure API without complex formation (b); and blank (blank: $0.1 \%$ formic acid in water (c)

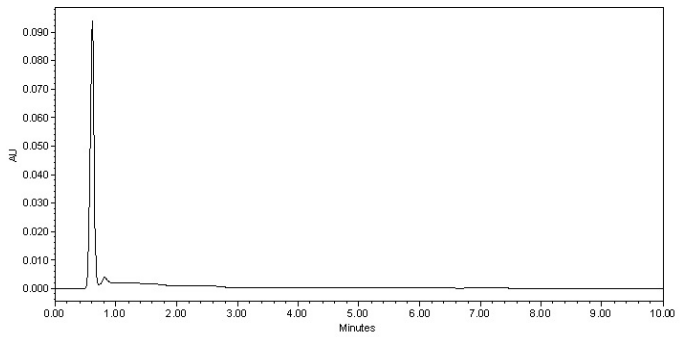

Figure 3: Representative chromatograms of mixture of iron (II) sulphate and copper (II) sulphate 
Table 1: Chromatographic parameters

\begin{tabular}{lcc}
\hline Parameter & D-PEN-Cu & DFX-Fe $^{2+}$ \\
\hline Retention time $(\mathrm{min})$ & 1.47 & 5.52 \\
Tailing factor & 1.08 & 1.39 \\
Resolution & 7.25 & 11.75 \\
Capacity factor & 2.45 & 4.49 \\
Theoretical plate count & 2528 & 2624 \\
RSD $(\mathrm{n}=6)(20 \mu \mathrm{g} / \mathrm{mL})$ & 0.46 & 0.92 \\
\hline
\end{tabular}

Table 2: Data on precision and accuracy

\begin{tabular}{|c|c|c|c|}
\hline Parameter & Concentration level & D-PEN-Cu ${ }^{2+}$ & DFX-Fe ${ }^{2+}$ \\
\hline \multicolumn{4}{|c|}{ Intra-day precision and accuracy ${ }^{2}$} \\
\hline \multirow{3}{*}{$\begin{array}{l}\text { Peak area RSD (\%) } \\
\text { (average recovery, \%) }\end{array}$} & LQC & $1.3(101.4)$ & $1.2(101.8)$ \\
\hline & MQC & $0.2(101.8)$ & $2.0(99.6)$ \\
\hline & HQC & $0.4(101.2)$ & $1.1(102.2)$ \\
\hline \multicolumn{4}{|c|}{ Inter-day precision and accuracy ${ }^{2}$} \\
\hline \multirow{3}{*}{$\begin{array}{l}\text { Peak area R.S.D. (\%) } \\
\text { (average recovery, \%) }\end{array}$} & LQC & $0.7(102.15)$ & $0.6(100.7)$ \\
\hline & MQC & $0.2(101.71)$ & $0.6(101.8)$ \\
\hline & HQC & $0.6(99.10)$ & $1.5(100.5)$ \\
\hline
\end{tabular}

${ }^{-a} n=3$; LQC, MQC, HQC - low, medium and high quality control sample concentration levels (16, 64 and 96 $\mu \mathrm{g} / \mathrm{mL}$, respectively)

Application of the developed method in determination of D-PEN in capsule and DFX in injection dosage forms

The validated HPLC method was used for determination of D-PEN and DFX in their capsule and injection dosage forms. The individual chromatograms for D-PEN and DFX in their respective dosage forms were compared with those recorded for placebo solution and blank chromatograms. The method was found to be specific since no peaks at the retention time of the drug complexes were observed. Accuracy studies on the respective formulations of D-PEN and DFX were carried out for sample recovery at three levels $(100 \pm 50 \%)$ of the targeted concentration $(40 \mu \mathrm{g} / \mathrm{mL})$.

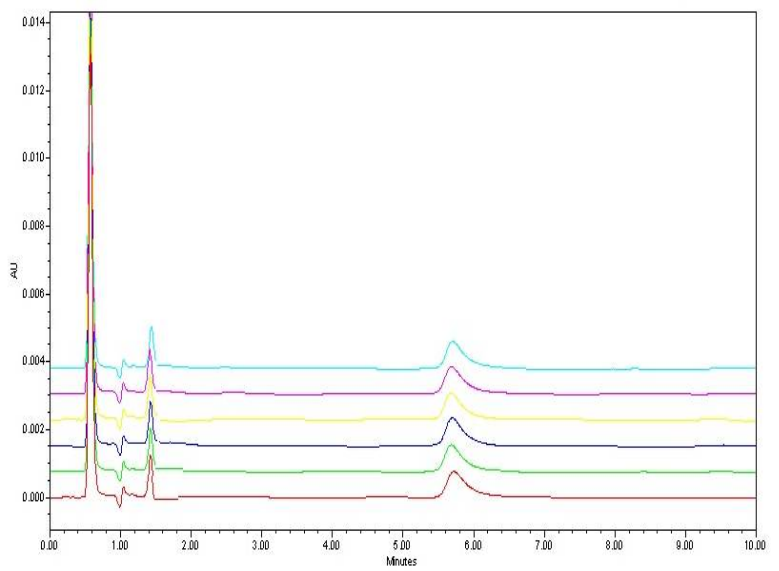

Figure 4: Representative chromatograms showing overlay of six replicate injections of standard solution containing a mixture of D-PEN-Cu ${ }^{2+}$ and DFX-Fe complexes, at LQC level $(16 \mu \mathrm{g} / \mathrm{mL})$
Table 3: Solution stability data

\begin{tabular}{lcc}
\hline $\begin{array}{l}\text { Analyte/ } \\
\text { complex }\end{array}$ & $\begin{array}{c}\text { Storage } \\
\text { conditions }\end{array}$ & $\begin{array}{c}\text { Mean recovery } \\
(\%)^{\mathrm{a}}\end{array}$ \\
\hline D-PEN & $20 \pm 2^{\circ} \mathrm{C} ; 7$ & 100.9 \\
& days & 100.1 \\
& $4^{\circ} \mathrm{C} ; 14$ days & 99.1 \\
& $-20^{\circ} \mathrm{C} ; 30$ days & 99.2 \\
DFX & $20 \pm 2^{\circ} \mathrm{C} ; 7$ & 100.3 \\
& days & 99.9 \\
\hline${ }^{\mathrm{a}} \mathrm{N}=6$ & $4^{\circ} \mathrm{C} ; 14$ days & \\
\hline
\end{tabular}

Table 4: Data on robustness

\begin{tabular}{lcc}
\hline \multirow{2}{*}{ Parameter } & \multicolumn{2}{c}{ Content (\%) $^{*}$} \\
\cline { 2 - 3 } $\begin{array}{l}\text { Ratio of } \\
\text { mobile phase } \\
(+5 \%)\end{array}$ & 100.3 & 99.8 \\
$\begin{array}{l}\text { Ratio of } \\
\text { mobile phase } \\
(-5 \%)\end{array}$ & 99.2 & \\
$\begin{array}{l}\text { Flow rate }(0.9 \\
\text { mL/min) }\end{array}$ & 98.8 & 101.2 \\
$\begin{array}{l}\text { Flow rate }(1.1 \\
\text { mL/min) }\end{array}$ & 99.4 & 99.1 \\
$\begin{array}{l}\text { Wavelength } \\
(255 \text { nm) }\end{array}$ & 101.3 & 98.3 \\
$\begin{array}{l}\text { Wavelength } \\
(265 \text { nm) }\end{array}$ & 98.7 & 98.7 \\
$\begin{array}{l}\text { Without } \\
\text { variation }\end{array}$ & 99.7 & 100.3 \\
\hline${ }^{*}$ The values are the average of three determinations
\end{tabular}

The mean percent recoveries of both analytes were within $100 \pm 2 \%$, which indicated the aptness of the developed method for estimation of D-PEN and DFX in their capsule and injection dosage forms. 
Table 5: Recovery data of D-PEN-Cu ${ }^{2+}$ and DFX-Fe ${ }^{2+}$ in capsule and injection dosage forms

\begin{tabular}{lcccc}
\hline Analyte & $\begin{array}{c}\text { Recovery } \\
\text { sample } \\
\text { concentration } \\
(\boldsymbol{\mu g} / \mathbf{m L})\end{array}$ & $\begin{array}{c}\text { Targeted } \\
\text { concentration } \\
(\%)\end{array}$ & $\begin{array}{c}\text { Drug } \\
\text { recovered } \\
(\boldsymbol{\mu g} / \mathbf{m L})\end{array}$ & $\begin{array}{c}\text { Recovery } \\
\text { R.S.D. } \\
(\%))^{\mathbf{a}}\end{array}$ \\
\hline D-PEN & 20 & 50 & 19.84 & $99.2 \pm 0.6$ \\
(capsule) & 40 & 100 & 39.56 & $98.9 \pm 0.2$ \\
\hline DFX & 60 & 150 & 60.6 & $101.0 \pm 0.7$ \\
(injection) & 20 & 50 & 19.78 & $98.9 \pm 1.1$ \\
& 40 & 100 & 40.75 & $101.9 \pm 0.1$ \\
\hline
\end{tabular}

${ }^{\mathrm{b}} n=6$
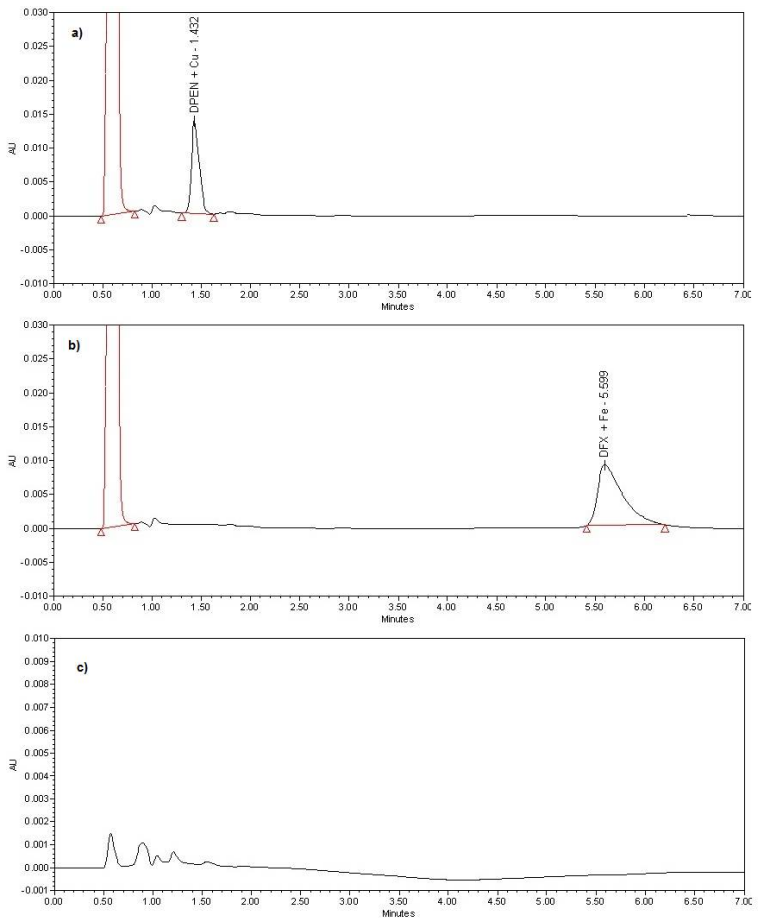

Figure 5: Representative chromatograms obtained from pharmaceutical formulations (capsule for D-PEN and injection for DFX) using the developed method a): D-PEN-Cu ${ }^{2+}$ complex; b): DFX-Fe ${ }^{2+}$ complex); c) placebo for D-penicillamine capsule

The calculated mean recovery data of D-PEN$\mathrm{Cu}^{2+}$ and DFX-Fe ${ }^{2+}$ in D-PEN and DFX formulations are summarized in Table 5 , while the representative individual chromatograms of D-PEN capsule, DFX injection and placebo are given in Figure 5.

\section{DISCUSSION}

The present research was undertaken in order to improve the UV-absorption of DFX and D-PEN by forming their complexes with different metal ions. No peaks were detected up to $7 \mathrm{~min}$ run time when pure DFX and D-PEN were injected into the HPLC system. This confirmed that these drugs cannot be detected directly by UV detector. Therefore, copper (II) chloride, copper (II) sulphate, iron (III) chloride and iron (II) sulphate were selected for improving the UV absorption of DFX and D-PEN by chelate formation. Different combinations of drug and metal ions were tested to find out the metal ion which forms a stable complex with drugs along with good and reproducible peak height and area. During the development of the method, no peak was detected up to 10 min of runtime when D-PEN was complexed with copper (II) chloride, iron (III) chloride as well as with iron (II) sulfate. Similar results were obtained when DFX was treated with copper (II) chloride, copper (II) sulfate and iron (III) chloride. However, when DPEN and DFX were complexed with copper (II) sulfate and iron (II) sulfate, respectively, two distinctly separated peaks at retention times of 1.47 and 5.52 min belonging to D-PEN-Cu ${ }^{2+}$ and DFX-Fe ${ }^{2+}$ complexes were observed.

After the selection, concentrations of metal ions were optimized with respect to DFX and D-PEN concentrations in order to obtain stable complexes. Different drug/metal ion molar concentration ratios of DFX and D-PEN (1:1, 1:2, $1: 5,1: 10$ and $1: 20)$ and their suitable metal ions $\left(\mathrm{Fe}^{2+}\right.$ and $\left.\mathrm{Cu}^{2+}\right)$ were investigated. At lower metal ion concentrations (1:1 and 1:2), lower peak areas were observed, whereas, at higher metal ion concentrations (1:10 and 1:20), remarkably broad peaks were obtained with a lot of noise. However, at 1:5 concentration ratio, symmetric and well separated peaks corresponding to DFX$\mathrm{Fe}^{2+}$ and D-PEN-Cu ${ }^{2+}$ complexes were achieved. As a result, five folds higher metal ion concentration than drug was found to be most optimum for quick formation of stable drug-metal ion complexes with acceptable peak shape.

In HPLC technique, the interaction between chelating drugs and metal ions can be achieved by using two approaches. In the first approach (in-column), chelating agents and metal ion solutions are premixed to allow for complex formation and then the resulting solutions are injected into the system for analysis, whereas, in the second approach (out-column), metal ion solutions are mixed with the mobile phase and 
the interaction between analyte/drug and metal ion takes place inside the HPLC column during the chromatographic run. In the present analysis, the first approach was successfully applied, wherein the solutions of DFX and D-PEN were mixed with $\mathrm{Fe}^{2+}$ and $\mathrm{Cu}^{2+}$ solutions, respectively, during the preparation of the sample/working solutions. The formed DFX-Fe ${ }^{2+}$ and D-PEN-Cu ${ }^{2+}$ complexes were then analyzed by injection into the HPLC system.

The second approach of complex formation was also studied during the development of the method, where the metal ion solutions were mixed with mobile phase (aqueous phase, i.e., $0.1 \%$ formic acid), and noisy chromatograms with multiple small peaks were obtained. Furthermore, the baseline noise was high and the acceptable system suitability parameters were not achieved.

The $\mathrm{pH}$ of the solution had significant influence on complexation process. Another solution which offered acceptable separation of analytes was ammonium formate buffer at $\mathrm{pH}$ 3.5. However, in this case, additional peaks were observed. Moreover, broad peaks of both complexes were seen, which might be due to the interference of ammonium ion with the drugs, resulting in adverse effects on the stability of the complexes. Hence, $0.1 \%$ formic acid was found to be most suitable to be used as the aqueous phase.

\section{CONCLUSION}

The chelating property of deferoxamine and $D$ penicillamine has been examined, and a suitable chromatographic technique has been developed for quantification of these drugs in their complexed forms with $\mathrm{Fe}^{2+}$ and $\mathrm{Cu}^{2+}$, respectively. The key improvement associated with the present method is that it provides fast and accurate analysis of D-PEN and DFX in bulk drugs as well as in capsule and injection formulations. The proposed method also offers a fast and easy complexation process that can be utilized for routine quality control analysis of these agents.

\section{DECLARATIONS}

\section{Acknowledgement}

This research work financially supported by Deanship of Scientific Research, Jazan University, Jazan, Saudi Arabia under WAED program.

\section{Conflict of Interest}

No conflict of interest associated with this work.

\section{Contribution of Authors}

The authors declare that this work was done by the authors named in this article and all liabilities pertaining to claims relating to the content of this article will be borne by them.

\section{REFERENCES}

1. Andersen 0 . Principles and recent developments in chelation treatment of metal intoxication. Chem Rev 1999; 99: 2683-2710.

2. Kumar V, Kumar A, Singh SK, Kumar M, Kumar S, Kumar D, Singh R. Chelating Drug Therapy: An Update. Austin J Genet Genomic Res 2015; 2: 1010-1015.

3. Flora SJS, Pachauri V. Chelation in Metal Intoxication. Int $J$ Environ Res Public Health 2010; 7: 2745-2788.

4. Hughes MF. Arsenic toxicity and potential mechanisms of action. Toxicol Lett 2002; 133: 1-16.

5. Carvalho CM, Chew EH, Hashemy SI, Lu J, Holmgren A. Inhibition of the human thioredoxin system. A molecular mechanism of mercury toxicity. J Biol Chem 2008; 283: 11913-11923.

6. Andress DL, Nebeker HG, Ott SM, Endres DB, Alfrey AC, Slatopolsky EA, Coburn JW, Sherrard DJ. Bone histologic response to deferoxamine in aluminumrelated bone disease. Kidney Int 1987; 31: 1344-1350.

7. Porter JB. Practical management of iron overload. $\mathrm{Br} J$ Haematol 2001; 115: 239-252.

8. Peck MG, Rogers JF, Rivenbark TF. Use of high doses of deferoxamine (Desferal) in an adult patient with acute iron over dosage. J Toxicol Clin Toxicol 1982; 19: 865869.

9. Camp AV. Penicillamine in the treatment of rheumatoid arthritis. Proc R Soc Med 1977; 70: 67-69.

10. Chiumiento $F$, D'Aloise A, Marchegiani $F$, Melai $V$. Determination of EDTA in feed and premix formulations by HPLC-DAD. Food Chem 2015; 175: 452-456.

11. Kord AS, Tumanova I, Matier WL. A novel HPLC method for determination of EDTA in a cataract inhibiting ophthalmic drug. J Pharm Biomed Anal 1995; 13: 575580.

12. Martin BR. Metal ion stabilities correlate with electron affinity rather than hardness or softness. Inorg. Chim. Acta 1998; 283: 30-36

13. Arshad B, lqbal T, Akram S, Mushtaq M. An expedient reverse-phase high-performance chromatography (RPHPLC) based method for high throughput analysis of deferoxamine and ferrioxamine in urine. Biomed Chromatogr 2017; 31: 1-6.

14. Singh S, Hider RC, Porter JB. Separation and identification of desferrioxamine and its iron chelating metabolites by high-performance liquid chromatography and fast atom bombardment mass spectrometry: choice

Trop J Pharm Res, February 2019; 18(2): 363 
of complexing agent and application to biological fluids. Anal Biochem 1990; 187: 212-219.

15. Glennon JD, Senior AT. Simultaneous determination of desferrioxamine and ferrioxamine by high performance liquid chromatography with amperometric detection. J Chromatogr B1990; 527: 481-489.

16. Kraemer HJ, Breithaupt $H$. Quantification of desferrioxamine, ferrioxamine and aluminoxamine by post-column derivatization high performance liquid chromatography. Non-linear calibration resulting from second-order reaction kinetics. J Chromatogr B1998; 710: 191-204.

17. Saracino MA, Cannistraci $C$, Bugamelli $F$, Morganti E, Neri l, Balestri R, Patrizi A, Raggi MA. A novel HPLCelectrochemical detection approach for the determination of $D$-penicillamine in skin specimens. Talanta 2013; 103: 355-360.

18. Bhushan R, Kumar R. Analytical and preparative enantio separation of DL-penicillamine and DL-cysteine by highperformance liquid chromatography on alpha-acid glycoprotein and beta-cyclodextrin columns using ninhydrin as a reversible tagging reagent. $J$ ChromatogrA 2009; 1216: 3413-3417.

19. Bhushan R, Bruckner $H$, Kumar V. Indirect resolution of enantiomers of penicillamine by TLC and HPLC using Marfey's reagent and its variants. Biomed Chromatogr 2007; 21: 1064-1068.

20. llisz I, Tourwe D, Armstrong DW, Peter A. Highperformance liquid chromatographic enantioseparation of unusual secondary amino acids on a D-penicillaminebased chiral ligand exchange column. Chirality 2006; 18: 539-543.

21. Yusof M, Neal R, Aykin N, Ercal N. High performance liquid chromatography analysis of D-penicillamine by derivatization with $\mathrm{N}$-(1-pyrenyl) maleimide (NPM). Biomed Chromatogr 2000; 14: 535-540.

22. Zhang ZD, Baeyens WRG, Zhang XR, Weken GV. HPLC determination of penicillamine in human urine applying a chemiluminescent detection system. Biomed Chromatogr 1997; 11: 113-114.

23. Sotgia S, Zinellu A, Pinna GA, Deiana L, Carru C. Application of an unusual ninhydrin-based reaction for the indirect chiral resolution of $D, L$-penicillamine. Talanta 2011; 85: 1783-1785.
24. Gholivand MB, Shamshipur M, Dehdashtian S, Adeh NB. Construction of a sensitive sensor for D-penicillamine using sodium montmorillonite nonoclay as a modifier. $\mathrm{J}$. Electroanal. Chem 2014; 725: 7-11.

25. Birus M, Bradic Z, Kujundzic N, Pribanic M. Iron(III) complexation by desferrioxamine $B$ in acidic aqueous solutions. Kinetics and mechanism of the formation and hydrolysis of the binuclear complex diferrioxamine $B$. Inorg Chem 1984; 23: 2170-2175.

26. Farkas E, Csoka H, Micera G, Dessi A. Copper (II), nickel (II), zinc (II), and molybdenum (VI) complexes of desferrioxamine $B$ in aqueous solution. $J$ Inorg Biochem 1997; 65: 281-286.

27. Stadtherr LG, Martin RB. Iron (II) and iron (III) complexes of penicillamine. Inorg Chem 1972; 11: 92-94.

28. Alhazmi HA, Alnami AM, Arishi AAA, Alameer RK, Bratty MA, Rehman ZU, Javed SA, Arbab IA. A Fast and Validated Reversed-Phase HPLC Method for Simultaneous Determination of Simvastatin, Atorvastatin, Telmisartan and Irbesartan in Bulk Drugs and Tablet Formulations. Sci. Pharm. 2018; 86; 1

29. Alhazmi HA, Moraya DA, Alahdal E, Kariri, M, Bratty MA, Rehman ZU, Javed SA. Ultrafast monolithic HPLC method for simultaneous quantification of anticancer agents, imatinib and sorafenib: Applications to tablet dosage forms. Trop. J. Pharm. Res. 2018; 17: 11271134.

30. Paul JM, Birker WL, Freeman HC. Structure, properties, and function of a copper (I)-copper (II) complex of $D$ penicillamine: pentathallium (I) .mu.8-chloro-dodeca (Dpenicillaminato) octacuprate (I) hexacuprate (II) $n$ hydrate. J Am Chem Soc 1977; 99: 6890-6899.

31. International Conference on Harmonization (ICH), Validation of Analytical Procedures: Text and Methodology, Q2 (R1),[homepage on the internet]. November 2005 [cited2017September 18]. Available from: http://www.ich.org/fileadmin/Public_Web_Site/ ICH_Products/Guidelines/Quality/Q2_R1/Step4/Q2_R1_ Guideline.pdf.

32. Center for Drug Evaluation and Research, US Food and Drug Administration. Reviewer Guidance, Validation of Chromatographic Methods [homepage on the internet]. FDA, Rockville (MD); November 1994[cited 2017 September 18]. Available from: https://www.fda.gov/ downloads/Drugs/Guidances/UCM134409.pdf. 